\title{
Language and Cognition: A Review Study about the Psycholinguistic of Bilingualism
}

\author{
Saddam H.M Issa ${ }^{1} \mathbf{8} \square$ and Fares H A Awadh ${ }^{2} \mathbf{8}$ \\ ${ }^{7}$ Assistant professor, College of Education, Hajjah University, Yemen \\ ${ }^{2}$ Kuwait College of Science and Technology, Kuwait \\ $\triangle$ Corresponding Author: Saddam H.M Issa, E-mail: sadgull67@gmail.com
}

\section{ARTICLE INFORMATION \\ Received: August 04, 2021 \\ Accepted: September 29, 2021 \\ Volume: 1 \\ Issue: 1 \\ DOI: 10.32996/jpbs.2021.1.1.3}

\section{KEYWORDS}

Bilingualism, psycholinguistics, cognition, language comprehension

\section{ABSTRACT}

To get a better understanding of the psycholinguistic approach to language, a wide range of sources were examined in the present research. Language and its cognitive approach were explored in this study from many perspectives. The capacity to learn a language is one of the most complex and distinctive human traits, and no one knows why it happens. It is hard to pin down exactly what bilingualism means since it is such a broad concept. The research of psycholinguistics made important discoveries, such as the need to have language information to utilise language and the mental processes involved. To better understand how two languages (L1, L2) are processed, this article discusses why only a few methods combine behavioural and imaging testing. Therefore, bilingualism cannot be considered a full attribute since no one can be granted a complete or minimum degree of proficiency in a second language.

\section{Introduction}

Bilingualism is a common occurrence in which more than half of the world's language speakers are thought to have some knowledge of a language that is somewhat or significantly different from their original tongue (Grosjean, 1982). Many nations, such as Canada, Belgium, and Switzerland, have a significant multilingual population. The study of bilingualism ideas has been a popular subject in psycholinguistics in recent years. Grosjean described it, stating that "the bilingual is not simply two monolinguals in one individual" in a 1989 article. Many academics have been drawn to this viewpoint in order to figure out how to modify language processing models, which were mainly monolingual at the time (Saddam. 2020).

Bilingualism is a well recognized term that has been defined in a number of ways. Bloomfield (1933) describes a bilingual person as someone who "has native-like use or control of two languages," however this definition is disputed since imbalanced bilinguals often have varying degrees of bilingualism. Bilingualism, according to Weisgerber (1937), is seen as strange and may impair an entire ethnic community's understanding. Weinreich (1953) adopts a more neutral stance, describing bilingualism as "a person who alternates between two languages" (p. 69). The degree of competence in the two languages used, the age of acquisition of the two languages, the social variables controlling the acquisition of the second language, and the environment that facilitates the acquisition of the second language are the most important factors determining the form of bilingualism that an individual has.

Bilingualism is a wide term that may be defined in a variety of ways. "Bilingualism exists in all nations of the globe, in every level of society, and in every age group," according to Grosjean (1982:1). Indeed, no language group has ever existed apart from other language groups, and the history of languages is littered with examples of linguistic contact that resulted in bilingualism. According to Shyamala (2005), many languages have coexisted in India from ancient times. As a consequence, India serves as a vibrant example of language spread and social bilingualism. This cohabitation and linguistic interaction has also resulted in it.

Bhat and Chengappa (2000:19) characterized bilingualism as "a fascinating subject and interaction between two languages, resulting to a combination of two languages." Furthermore, according to Chengappa (1986: 6), "bilingualism is dependent on a number of factors, including the ontological milestone and the simultaneous acquisition of two or more languages, motivation, duration, functions associated with each language, the separation of functions between the languages acquired, and so on."

\section{K C AL-KINDI CENTER R D FOR RESEARCH AND} Your gateway to world-class research

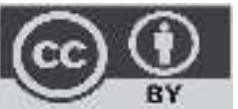

Published by Al-Kindi Center for Research and Development, London, United Kingdom. Copyright (c) the author(s). This open access article is distributed under a Creative Commons Attribution (CC-BY) 4.0 license 
Within the field of language learning research, the basic idea of bilingualism has been divided into three categories: (1) daily language use, (2) length of birth exposure, and (3) ability and competence in more than one language (Grech and McLeod 2012). These discrepancies have major implications for the sampling and subsequent interpretation of the research' findings. Being bilingual entails having several lexical representations that enable a bilingual to express the same idea in different ways. To reply to a barking pet, Arabic-English bilinguals, for example (bilinguals whose native language is Arabic and whose second language is English), may use the Arabic term Kalb or the English word dog. These lexical representations will be regarded as bilingual, with two distinct lexicons (mental dictionaries): one lexicon holding all the terms of its home language (L1), and one glossary containing the words of its target language (L1) (L2).

Because no one can be awarded a complete or minimal degree of competence in a second language, bilingualism cannot be regarded a whole property. This is often referred to as mastery. This raises the difficulty of identifying the degree of twolanguage proficiency, which is crucial in bilingualism research. A language's competence level is determined by four factors: understanding, speaking, reading, and writing. People may be categorized as balanced bilinguals or dominating bilinguals based on their abilities in both languages. Bilinguals are equally skilled in both languages, although dominant bilinguals are more common in one. Bruner (1967) stated that bilingual language community balance is seldom seen because bilingual people rarely have the same proficiency in both languages across all language abilities. Weinreich (1953) identified three kinds of bilingualism based on how bilinguals learn languages: compound, co-ordinate, and bilingual sub-coordinate.

A compound bilingual is someone who speaks both languages in the same context and surroundings in order to learn two different verbal expressions for the same concept.

i. The co-ordinate bilingual is someone who learns the two languages in a variety of settings (e.g., school and home) such that their vocabularies are different and independent.

ii. A subordinate bilingual is someone who can utilize one language in a larger context than the other.

Weinrich proposes these three kinds of bilingualism in his study of bilingual literature (Paradis 1978). The first kind of bilingualism is coordinated bilingualism, which is defined by sound pictures and meaning units. A coordinate bilingual, in other words, has two sets of meanings and matching words. The second kind of bilingualism is compound bilingualism, in which the bilingual has one unit of meaning but two distinct units of vocabulary. As a result, the meanings of both languages will be combined in a compound multilingual. He/she may express himself/herself using both languages' remarks. Subordinate bilingualism is the final kind, in which the bilingual possesses an equivalent unit of both the meaning unit and the associated sound image of both the mother tongue and the second language. In order to comprehend the many kinds of bilingualism, we must also be acquainted with the various categories of bilingualism. This may be further developed and clarified via a thorough examination of the major differences between the various kinds of bilingualism.

Bilinguals may also be divided into groups depending on the social variables that influence language acquisition (Fisherman 1972). Bilinguals were suggested to be divided into two groups: bilingual people and bilingual elite. Bilingual people are also speakers of a particular language that lacks the social importance and prestige of their peers in the dominant language culture. Elite bilinguals, on the other hand, are language speakers whose native language is dominant in a society and who can use another language with social significance and benefit. Elite bilinguals are those who have learned a second language via formal education and natural use of the language. Folk bilinguals are people who have learned a second language by practical contact with native speakers of that language (Skutnabb-Kangas 1981).

Bilingualism may be classified into early and late bilingualism based on the age of acquisition, according to Cohen (1976). Early bilingualism is described as the learning of more than one language in the early stages of life, such as childhood. Late bilingualism is defined as the learning of one language before the other (the second language must be learned beyond the age of seven years) (Baetens Beardsmore, 1986: 28). Based on the bilingual's language competency accomplishment, a difference may be established between early and late bilinguals. An early bilingual is a bilingual who has acquired native-like verbal proficiency in both languages. As a result, early bilingualism is defined as learning a language as a first language (Swain 1972). Most late bilinguals, on the other hand, are non-native L2 speakers who have not yet fully mastered the language (Baetens Beardsmore, 1986).

Haugen (1973) proposed a new concept of bilingualism, referring to balanced and dominating bilinguals. A balanced bilingual is described as a person who possesses native-like abilities in both languages, according to various writers (Haugen 1973). As a result, a healthy bilingual is one whose skills in both language tend to be similar and whose success in both languages is uneven. By looking at the connection between fluency and proficiency in bilinguals who have mastered their respective languages, we can explain the difference between healthy and dominating (or imbalanced) bilinguals (Peal and Lambert, 1962).

The following figure illustrates the different types and classifications of bilingualism proposed by various researchers based on skills and social context. 


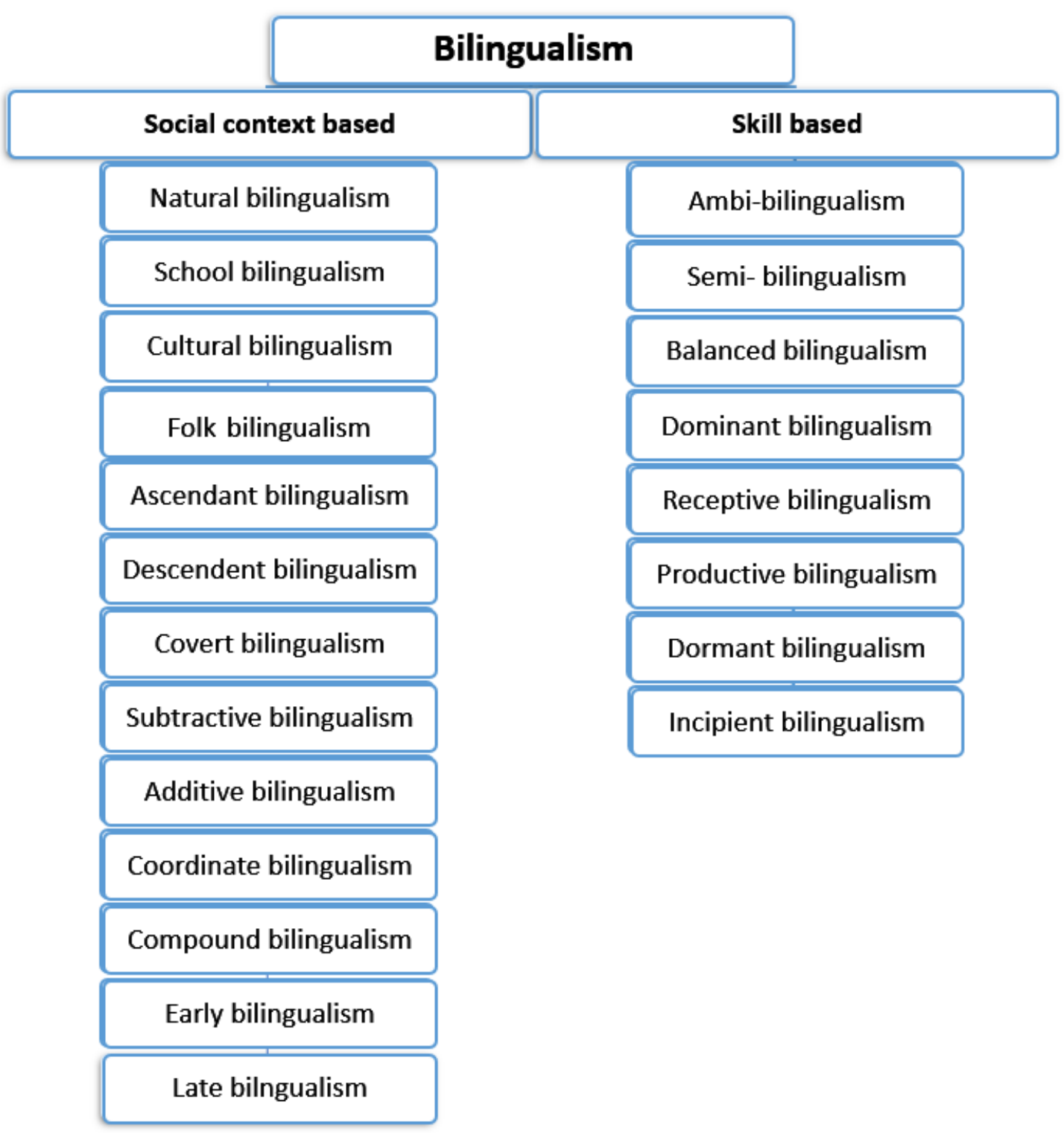

Figure 1. Different types of bilingualism based on skill use and social context.

As communication and related cognitive processes are the most linked, dynamic, and essential human activity, language and thinking have been a major scientific interest and fascinating subject of research. Human communication is the most dynamic and amazing creation that humanity has created. In the beginning, language and communication offer a basic series of senderreceiver exchanges. Despite this, many current research in language and communication are still attempting to define the whole system as well as the complex processes involved in the human brain. Language functions as an embedded cognitive system and as a unit for understanding information. "All higher mental processes and actions needed to comprehend, remember, consider, and understand language" are referred to as cognition (Ashcraft \& Radvansky, 2010). The basic elements of human thinking and communication are concepts and meanings (semantics). Communication is widely acknowledged as an important component of human behavior. Jonassen (2000) defines it as "the transmission and interchange of information that takes various forms and serves many objectives" (p. 22). Communication is the process of sharing information, ideas, attitudes, perceptions, and emotions with others (Wood, 1976). Communication encompasses a wide range of information since it relates to all of the instruments that an individual employs to communicate with other people or the community. In general, communication is divided into two types: purposeful and inadvertent. The purposeful mode comprises spoken and written language, whereas the inadvertent mode includes facial expression, eye contact, and body posture. A symbol system is usually used to symbolize communication in order to share data. When words are used, communication is referred to as linguistic; when other sign systems are employed, communication is referred to as non-linguistic. The notion serves as the foundation for all of these modalities of communication, and the mechanism by which this idea is communicated is required. The 
psycholinguistics approach is concerned with all aspects of the communication process, including language production, understanding, and learning.

\section{Psycholinguistics}

The primary focus of psycholinguistics, the scientific study of linguistic mental characteristics, is on the learning, use, and creation of human language. This branch of linguistics is a study field whose main aim is to develop and comprehend a coherent theory of language (Alan Garnham. A, 1983). Psycholinguistics emerged as an interdisciplinary field in the twentieth century, focusing on the cerebral foundations of language usage. Every linguist and psycholinguist has looked at the factors that influence the current structure of etymological and lexical information (Miller and Johnson-Laird 1976). The exact awareness of language information needed for language use, as well as the cognitive processes involved in regular language usage, are important areas in psycholinguistic research. To utilize a language, for example, we must have some understanding of it, and we must all be aware of this understanding. David Carrol (David Carrol, 2008). Reading a book, comprehending a lecture, leading a debate, and writing a letter all need cognitive functions like memory, perception, and reasoning. When you perform simple activities like speaking and listening, you may notice that many cognitive processing systems are engaged.

Many linguistic issues (e.g., comprehension, development, speech reading, understanding, etc. ), demographics (e.g., monolingual, bilingual, etc.) and methods (e.g., behavioral, neuroimaging, neuropsychological, etc.) are related to the study of language organization and word processing (Navarrete, Del Prato, Peressotti, \& Mahon, 2014). Over the past two decades, I've completed language processing research to experimentally test and demonstrate whether transformational grammar is psychologically correct. They developed their techniques for investigating language organization issues independent of any specific linguistic theory (Jiang 2012).

This multidisciplinary discipline of linguistics derives information and ideas from a number of related fields (e.g., semantics, phonetics, and pure linguistics), all of which are linked to cognitive studies of language processing. In addition, there is a close relationship between psycholinguists and neurolinguists who focus on language recognition. Both of them are interested in how the brain represents language. In contrast to psycholinguistics, neurolinguistics provides the psycholinguist with additional study opportunities. It gains a comprehensive understanding of the potential of studying language processing neuronal mass activity. Works linked to brain association in psycholinguistics may collaborate to match behavioral findings and lead to direct material regarding the fundamental foundation of psycholinguistics processes. The artificial intelligence goal of developing computer systems that convert expression into text and algorithms that comprehend human expression sparked interest in language processing (John Field 2003).

Psycholinguistics' primary concerns, from which cognitive processes are inferred, are reaction time and button push task studies (Friedmann Pulvermüller 2007). Cognitive processes addressed by psycholinguistic research may be used to understand utterances and words, as well as generate grammatical and substantive sentences from words and grammatical structures. As a result, academics from many disciplines, such as cognitive science and psychology, study psycholinguistics, an interdisciplinary branch of linguistics. This subject is divided into many subcategories depending on the components of human language. Many linguistic issues have benefited from psycholinguistic research (e.g., language understanding, language production and language perception of speech). As a result, each of these language components must be addressed separately in order to demonstrate how psycholinguistics approaches these linguistic problems.

\section{Language Comprehension}

Language comprehension is a complex process that necessitates the coordination of several cognitive functions (e.g., perceiving letters and words, determining and incorporating word meanings to interpret thoughts and ideas, and incorporating existing information to construct a given representation situation). (2016, Allison A. Steen). Understanding what people say and write is a more unexpected process than it seems at first. It encompasses a variety of procedures, knowledge, skills, and talents that are used to extract meaning from spoken or written languages. Language comprehension and understanding is a complex process that individuals do with ease and efficiency. It grows in tandem with the brain and may be aided by the use of signals. Language comprehension includes the use of acoustic aspects of speech to create mental representations of meanings, events, and circumstances in both spoken and written communication.

Language comprehension is a hot subject in today's cognitive linguistics. The capacity to correctly arrange and utter sounds and word meanings is the foundation for activities linked to language comprehension and understanding. Comprehending spoken and written languages relies on sentence and discourse or text grammar, although any problem in any area may create difficulty understanding. Language comprehension is made up of a number of basic components that aid in language comprehension. The fundamental components of language comprehension are becoming more important in picking up meaning depending on what is being read, as illustrated in the accompanying diagram. 


\section{LANGUAGE COMPREHENSION}

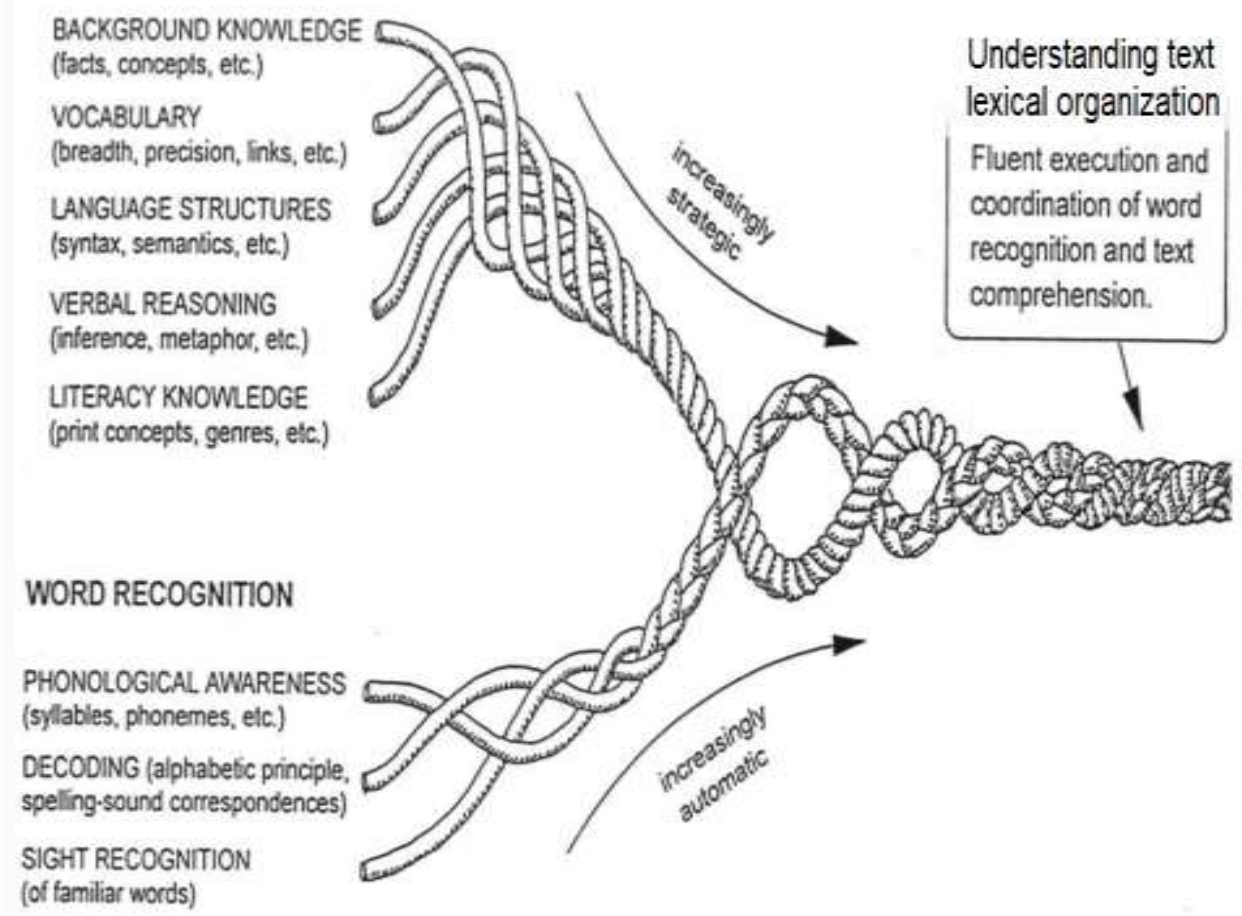

\section{Understanding text lexical organization}

Fluent execution and coordination of word cognition and text comprehension

Figure 2: Fundamental segments of language comprehension. Source (Connecting early language and literacy to later reading (dis)abilities: Evidence, theory, and practice, by H. S. Scarborough, in S. B. Newman \& D. K. Dickinson (Eds.), 2002, Handbook of early literacy research.

Language comprehension and word recognition are given as two important components of effective comprehension of language ideas provided in a text during, for example, language reading (Scarborough 2002). In fact, owing to its sub basic abilities or segments, each of the components is complicated. Language comprehension, according to prior research, consists of fundamental skills and threads like as (context awareness, vocabulary, verbal logic and knowledge of literacy). It also requires a thorough grasp of how to use these skills or parts to reading and comprehending a specific piece of information given in a text. Because the second main component is word recognition, this component must continuously gather a critical basis of foundation knowledge regarding many elements like as (phonological awareness, decoding of spelling sounds and sight recognition of familiar words). A good language comprehension will result from the appropriate usage of all of these parts.

When discussing language comprehension, there is enough opportunity to discuss the brain's different areas and their importance. The right and left hemispheres of the brain are referred to as brain hemispheres. The left side of the human brain is regulated by the right hemisphere, whereas the right side is regulated by the left side of the brain. The "Broca's and Wernicke's areas" are two main regions in the left hemisphere of the human brain that are recognized to be the two most important language centers. In the brain, these regions regulate language understanding and production. Broca's and Wernicke's regions of the brain, also known as Broca's and Wernicke's areas, were discovered by two renowned doctors called "Paul Broca and Carl Wernicke" in the 19th century. 


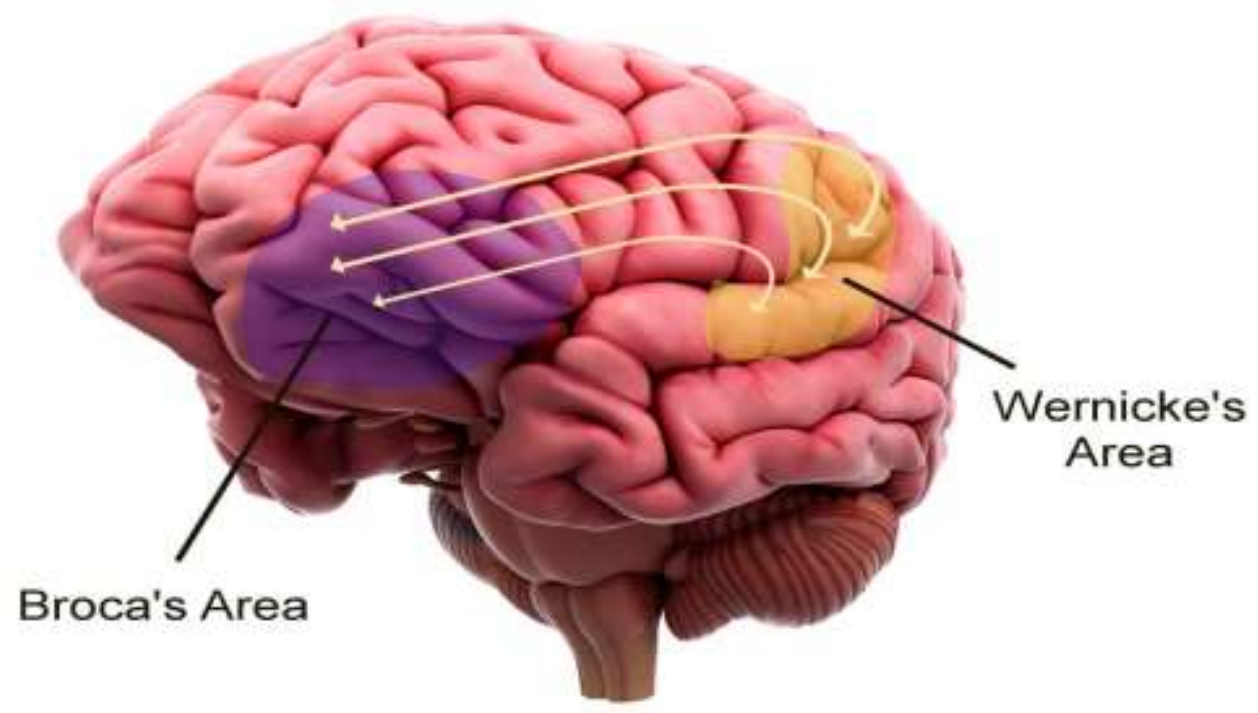

Figure 3: Broca's and Wernicke's areas

Source (Difference between Broca's area and Wernicke's area in the brain, by Thadphoothon, J. (2019)

Wernicke's region is the portion of the brain that is important for the formation of language. It is found on the left side of the brain's temporal lobe. Wernicke's region is critical for language comprehension, language growth, and language usage, and any damage to this part of the brain may seriously impair these functions. Wernicke's aphasia is a language problem caused by damage to this region of the brain. Wernicke's aphasia is a condition in which a person has trouble comprehending spoken language since this region of the brain is responsible for sound and word processing. The individual with such a language disability may make noises, words, and sentences, but they have no meaning since no information is transmitted. We may say that Wernicke's region allows us to create sounds, and this zone also contains the meaning and comprehension of the words we hear. Patients with aphasia lose their language skills fully or partly depending on which region of the brain is affected by the injury. This includes the capacity to produce spontaneous speech, identify objects, comprehend speech, repeat, write, and read.

Broca's region, on the other hand, is situated on the left side of the equator, where the temporal lobes and the frontal-parietal are linked. The articulation of words and phrases is handled by this portion of the brain. Patients with Broca's aphasia may understand words and phrases but are unable to distinguish between meanings (Nushi and Juniku, 2006, p.163). Broca's diseases differ from Wernicke's in that they do not affect fluency or understanding of language. This section is in charge of syntactic problems including language structure and word and sentence articulation (Language production).

\section{Language production}

One of the determinants of a person's competency in a speech is their ability to speak a language fluently. This skill is often seen in the mother language of the speaker. Language production is, unsurprisingly, regarded as one of the most important focal areas in psycholinguistics, language learning, and language comprehension. Language production research is rare compared to language comprehension research. It is said that researching language comprehension is easier than investigating language creation, therefore comprehension has been researched more extensively" (Garnham 1985). Because of this lack of focus on language creation, a small number of psycholinguistic studies have tried to explain how language is created by the speaker and how sounds and words emerge from the mind via the lips. These research on language production have tried to clarify the system's efficacy. As a result, they've tried to figure out how a typical speaker can convey language at a pace of 2 to 3 words per second, or 120 to 200 words per minute.

Levelt $(1989,1993)$ suggested several processing components that are involved in spoken language usage. Levelt's $(1989,1993)$ speech production system is made up of many self-governing components that focus on different aspects of language creation. The conceptualizer is a component that is in charge of generating and monitoring communications. The formulator, which is in charge of providing communications linguistic and phonological shape and maintaining the vocabulary, is one of Levelt's suggested components. It also contains the articulator, which is a key component in the production and use of language and plays a key role in the motor execution of the message. It highlights the technique of speech understanding by converting auditory information into phonetic forms.

The conceptualizer, as previously said, is in charge of creating messages and keeping track of the whole language growth process. In Levelt's suggested paradigm, speakers may comprehend and express their thoughts in the same way as they process 
and listen to others' speech, thanks to their comprehension system. What matters is that the speakers have entered their own distinct and inner discourse. The pre-verbal approach should be evaluated from the outset in the event of an internal voice, depending on the speaker's goal. The articulatory technique would then be placed in working memory, where it would be evaluated shortly after.

In addition, unless an incorrect item is conveyed, the speaker may identify errors. In terms of open expression, the hearing component understands uttered words and retrieves their meanings using the speech comprehension technique. Learners would be able to manage both the context and the well-formedness of their produced vocabulary in this way. When a problem is recognized, there are many options for dealing with it, including ignoring it, changing the pre-verbal response, or creating a new message. It means that if someone has to come up with a term, they must pay attention to what they want to convey. The speaker then chooses the relevant information from his or her brain's knowledge. Beginning with word collecting and ending with phonological encoding of the word, Figure 3 depicts the different stages of language development in detail.

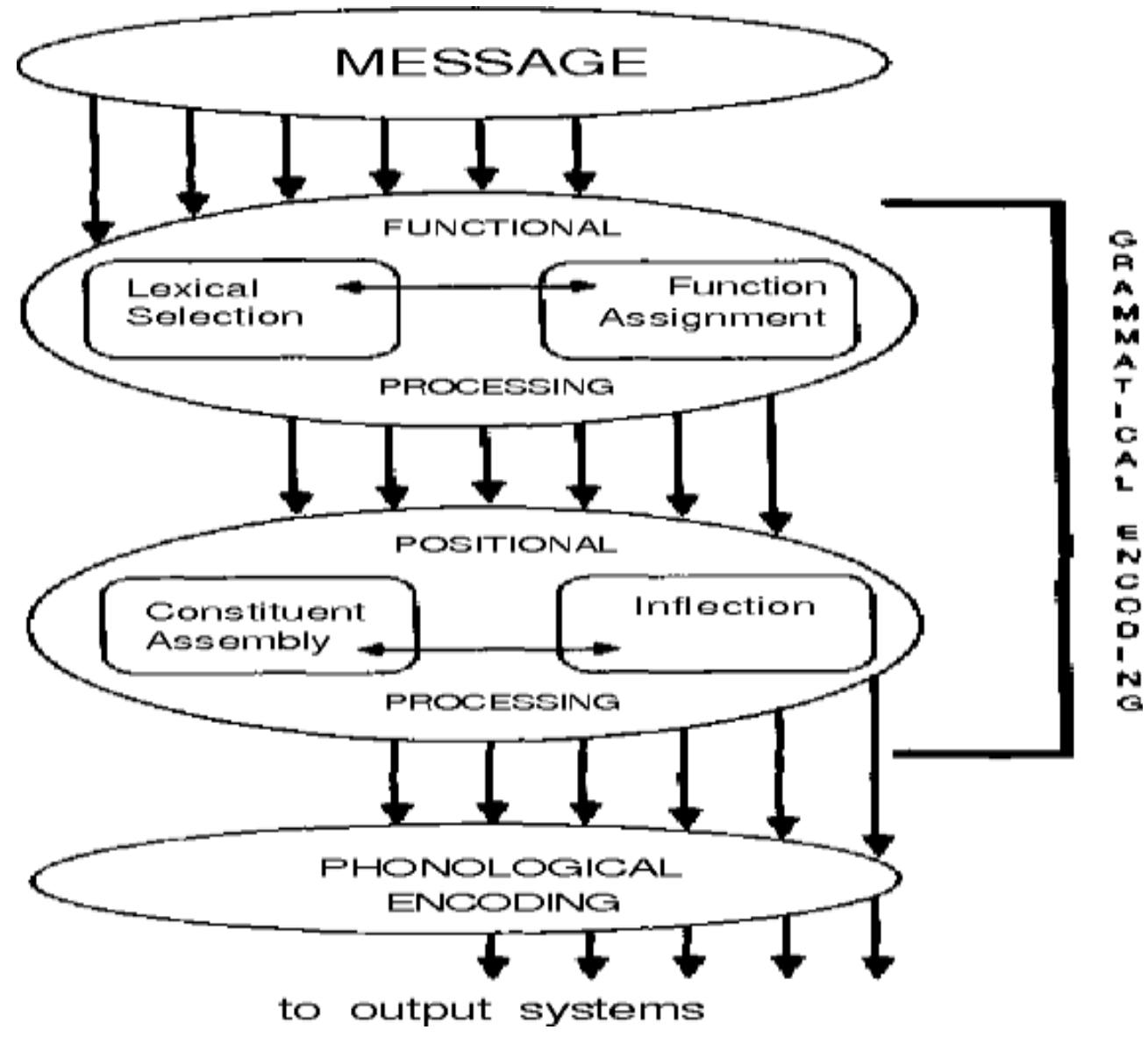

Figure 4. Level method of speech production.

Source: "Language Production A Presentation for a Course in Psycholinguistics", Waleed Khalid, (2018), University of Babylon, P.10.

A message-level representation is the first step in the speaking process. The speaker captures the concept he wants to communicate; at the other end of the model, the message is converted to sound through phonological encoding. The first, known as functional processing, and the second, known as positional processing, are two methods for syntactic handling (or grammatical encoding, as shown in the diagram). They focus on connecting the phonological levels to the message.

\section{Language Acquisition}

The many methods and procedures used by a kid to learn language are referred to as language acquisition (Lidz, Jeffrey; Waxman 2003). These strategies are in charge of perceiving and comprehending language. Language acquisition is concerned with how a language's words and sentences are utilized in communication. It just occurs in a predictable manner that is aided and assessed as anticipated developmental milestones (Seidenberg, M.S.1997). When a kid starts to develop the most fundamental talents and learn the necessary language skills, this is referred to as first language acquisition. The most basic 
language abilities that a kid develops throughout the language acquisition process are word comprehension, understanding the significance of grammar, generating sounds, and expressing ideas (Lightfoot, David 2010). Following that, based on the fundamental abilities learned before, various new languages may be learned easily and without misunderstanding. Language acquisition is a branch of psycholinguistics that studies how individuals learn to speak and acquire language. It primarily focuses on the many mental processes that allow us to interact with others. Language acquisition looks at whether we are taught to speak by others around us or whether we are born with all of the necessary inherent skills in our brains to let us learn languages.

Language acquisition is a dynamic and unique human trait for which no theory has yet been developed capable of fully explaining how language is acquired. As a result, the majority of theories and hypotheses on how languages are learned are regarded as techniques presented by academics such as Skinner, Chomsky, Piaget, and others. Noam Chomsky is a prominent thinker who has made significant contributions to the area of language learning. He thinks that our brains contain pre-wired mechanisms that allow us to learn sophisticated language skills (Chomsky, N., 1965). We do not learn a language by accident, but rather by following a set of rules. Children look for common speech patterns and utilize them as a starting point for experimenting with new phrases, such as adding the past tense '-ed' to words like 'work.' Chomsky went on to think that humans are born with inherent skills, or "switches," that may be set differently depending on the language variety (Chomsky, N., 1965). A concept like word order may change depending on which language is utilized.

Language acquisition problems seem to make it impossible to comprehend anything about a specific language without first knowing language in general. It implies that before recovering the data he displays in his surroundings and assigning meaning to the words he meets, the kid must be acquainted with the language and know what to expect. Early bilinguals go through a series of phases in their first five years of life, which is regarded one of the most compelling arguments for the idea of genetic programming of language learning. In reality, there are aspects of each era that haven't changed. Only nouns and verbs, for example, may be predicted at the two-word level. While studying these sets of words in his context, no kid begins to use conjunctions or prepositions. Another distinct function is overextension, which occurs when youngsters continue to acquire vocabulary by extending the meanings of words.

The expanded usage of the term dog for all animals if the first animal they are introduced with is a dog is a good example. Other examples include calling all elderly men dada or calling anything spherical a ball. The children here go from a broad idea to a specific one. Their language, for starters, is identical at all linguistic levels. As they get more acquainted with the setting in which they are working, they will offer more and more distinctions.

The stages of language acquisition for children are organized in a systematic order based on the child's age. The language stage, for example, is marked by the gradual acquisition of specific language abilities. We can anticipate and identify the appropriate stage of language learning using certain developmental skills. The following are examples of these stages:

Table 1: Stages of language acquisition in children

Source (Mathew Saxton 2010)

\begin{tabular}{|c|c|}
\hline Age (Months) & Linguistic Milestones \\
\hline $\mathbf{o}$ & $\begin{array}{l}\text { - Recognition and preference of mother's voice (even from inside the wombl) } \\
\text { - Ability to distinguish phonemes } \\
\text { - Can distinguish own language from a foreign language }\end{array}$ \\
\hline 7 & $\begin{array}{l}\text { - Early babbling is seen } \\
\text { - Start to understand first words (e.g. Mummy) }\end{array}$ \\
\hline 12 & $\begin{array}{l}\text { - Jargoning (when babbling becomes more specified to the child's mother tongue: } \\
\text { stress and intonation patterns are recognisable) } \\
\text { " First words produced }\end{array}$ \\
\hline 18 & $\begin{array}{l}\text { - Understand around } 50 \text { words } \\
\text { - Produce two-word utterances }\end{array}$ \\
\hline 24 & - Multi word utterances produced with basic grammatical features \\
\hline 60 & $\begin{array}{l}\text { - 6,000 word capacity } \\
\text { - Ability to produce complex sentences has been gained, with full comprehension }\end{array}$ \\
\hline
\end{tabular}




\section{Conclusion}

The current study was carried out with the aim of providing a general insight about the psycholinguistic approach of language therefore, a great number of sources were gone through. The paper showed the different views and concepts related to the notion of language and its cognitive approach. The ability to acquire a language is a complicated and unique human characteristic for which there is no complete explanation. As a consequence, views put forward by academics like Skinner, Chomsky, Piaget, and others are widely accepted as the mainstream view on language learning. Noam Chomsky is a pioneering thinker in the field of language acquisition who has had a major impact.

The Important findings of the study in psycholinguistics include the knowledge of language information required for language use and the cognitive processes involved. This paper explains the concept of why only a few of the techniques used include behavioural and imaging tests to see how the two languages (L1, L2) are processed, structured, and retrieved. Many subjects, including systemic organization and how the two languages of a bilingual are coordinated or processed, have been the subject of intensive research in this field. Another problem related to the two languages' processing (Jared and Kroll, 2001). Psycholinguistic research contributes new insights into how speakers knowing more than one language organize and process their languages. When a bilingual subject is speaking in one language, the other language (or languages) are always active to some extent. We must all be conscious of our knowledge of a language before we can effectively use it. Rory O'Malley (David Carrol, 2008). Performing cognitive tasks like reading and understanding a book, leading a discussion, and composing a letter all need mental abilities like memory and perception. You may be surprised to learn how many cognitive processing systems are in use when you do something as basic as speaking or listening out loud.

It's a well-known fact that the word "bilingualism" may be defined in a variety of ways. It has been argued that Bloomfield's (1933) definition of a bilingual individual is contested since unbalanced bilinguals frequently have different levels of bilingualism. According to Weisgerber (1937), bilingualism is seen as odd and may damage the comprehension of a whole ethnic group. According to Weinreich (1953), bilingualism is defined as "a person who switches between two languages" (p. 69). To a large extent, the level of proficiency in both languages, age of acquisition, social variables influencing second language learning, and environment all have a role in defining a person's level of bilingualism. However, there are other aspects to consider as well.

\section{References}

[1] Bahrani, T., \& Sim, T. S. (2012). Informal Language Learning Setting: Technology or Social Interaction?. Turkish Online Journal of Educational Technology-TOJET, 11(2), 142-149.

[2] Chee, M. W., Caplan, D., Soon, C. S., Sriram, N., Tan, E. W., Thiel, T., \& Weekes, B. (1999). Processing of visually presented sentences in Mandarin and English studied with fMRI. Neuron, 23(1), 127-137.

[3] Collins, A. M., \& Quillian, M. R. (1969). Retrieval time from semantic memory. Journal of verbal learning and verbal behavior, 8(2), $240-247$.

[4] Costa, A., Miozzo, M., \& Caramazza, A. (1999). Lexical selection in bilinguals: Do words in the bilingual's two lexicons compete for selection?. Journal of Memory and language, 41(3), 365-397.

[5] Costa, A. (2005). Lexical access in bilingual production In Kroll JF \& De Groot AMB (Eds.), Handbook of bilingualism: Psycholinguistic approaches (pp. 308-325).

[6] Costa, A., Albareda, B., \& Santesteban, M. (2008). Assessing the presence of lexical competition across languages: Evidence from the Stroop task. Bilingualism, 17(1), 121.

[7] Dehaene, S., Dupoux, E., Mehler, J., Cohen, L., Paulesu, E., Perani, D., ... \& Le Bihan, D. (1997). Anatomical variability in the cortical representation of first and second language. Neuroreport, 8(17), 3809-3815.

[8] De Groot, A. M., \& Kroll, J. F. (Eds.). (2014). Tutorials in bilingualism: Psycholinguistic perspectives. Psychology Press.

[9] Dijkstra, T. (2001). What we know about bilingual word recognition: A review of studies and models. In Proceedings of the Plenary Address at the International Symposium on Bilingualism.

[10] Dijkstra, T., Timmermans, M., \& Schriefers, H. (2000). On being blinded by your other language: Effects of task demands on interlingual homograph recognition. Journal of Memory and Language, 42(4), 445-464.

[11] Dijkstra, A. F. J., \& Van Heuven, W. J. (2002). The architecture of the bilingual word recognition system: From identification to decision.

[12] Duyck, W., \& Brysbaert, M. (2002). Forward and backward number translation requires conceptual mediation in both balanced and unbalanced bilinguals. Journal of Experimental Psychology: Human Perception and Performance, 30(5), 889.

[13] Elyas, T., \& Mahboob, A. (2014). English in the Kingdom of Saudi Arabia. World Englishes, 33(1), 128-142.

[14] Giles, H., \& Williams, A. (1994). Patronizing the young: Forms and evaluations. The International Journal of Aging and Human Development, 39(1), 33-53.

[15] Green, D. W. (1998). Mental control of the bilingual lexico-semantic system. Bilingualism: Language and cognition, 1(2), 67-81.

[16] Grosjean, F. (1982). Life with two languages: An introduction to bilingualism. Harvard University Press.

[17] Grosjean, F. (1997). Processing mixed language: Issues, findings, and models. Tutorials in bilingualism: Psycholinguistic perspectives, 225254.

[18] Issa, S. H., \& Shyamala, K. C. (2021). Investigating the Speed of Lexical Activation in the Bilinguals' L1 and L2 through Forward and Backward Translation Task. International Journal of English Language Studies, 3(3), 26-34.

[19] Issa, S. H., \& Shyamala, K. C. (2020). LEXICAL ACTIVATION IN HIGH AND LOW PROFICIENT BILINGUALS (ARABIC-ENGLISH) ON FREE NAMING TASK. PalArch's Journal of Archaeology of Egypt/Egyptology, 17(6), 1251-1266. 